\title{
Environmental Education for Children in Taiwan: Importance, Purpose and Teaching Methods
}

\author{
Yan-Hong Ye ${ }^{1}$, Yi-Huang Shih ${ }^{2, *}$ \\ ${ }^{1}$ Teacher Education Center, Ming Chuan University, Taiwan \\ ${ }^{2}$ Department of Early Childhood Educare, Ching Kuo Institute of Management and Health, Taiwan
}

Received January 17, 2020; Revised March 17, 2020; Accepted March 28, 2020

Copyright $\bigcirc 2020$ by authors, all rights reserved. Authors agree that this article remains permanently open access under the terms of the Creative Commons Attribution License 4.0 International License

\begin{abstract}
There is an increase in social issues in terms of the use of technology for environmental protection, energy, reproduction, food, ethics and morality. It is necessary to take advantage of the positive benefits of technological development and decrease its negative impact on the environment. In this regard, children must be taught appropriate responses to the environment. This should be taken as a key element of environmental education. Furthermore, environmental ethics is a core concept in environmental education for children. Environmental education seeks to teach children ethical environmental beliefs so that future citizens are environmentally aware. This paper uses a documentary analysis to show the importance and purpose of environmental education and explores the teaching methods for environmental education for children in Taiwan. The teaching methods of learning environmental awareness to children in environmental education lessons are: (1) using picture books, (2) watching eco-related films, (3) drama teaching and learning, (4) visiting environmental sites, (5) inviting experts to give presentations, (6) assigning homework that has environment-related topics, (7) cultivating critical thinking about the use of learning strategies in environmental education and (8) learning strategies that involve problem-solving.
\end{abstract}

Keywords Environmental Education, Environmental Ethics, Teaching Methods

\section{Introduction}

An increase in ecological and environmental problems has seen a focus on sustainable development over the past three decades. The common consensus is that education can significantly change human attitudes, values and behaviors to increase environmental literacy and deal with environmental problems to achieve sustainable development goals (Jen \& Hsu, 2007). Stables (2003) also noted in "Education for Diversity: Making Differences" that children should be encouraged to take more responsibility for the environment in their hometown and extend this to global ecological care.

Human is by nature a learning individual. Humans are self-cultivating, self-reflective, self-conditioning individuals who develop natural potentialities and exercise distinctively human functions only insofar as they live a meaningful life. Human is largely a self-formed being that is capable of the diverse forms of learning. Children are by nature learning individuals, because they are self-cultivating, self-reflective, self-conditioning individuals who seek to fully develop their natural potentialities. Children are also largely self-formed individuals who are capable of the diverse forms of learning, so environmental education produces specific learning outcomes for children (Yen, Ferng, \& Liu, 2006).

As the foundation of elementary education in Taiwan, environmental education aims to develop the essential knowledge, skills and attitudes that required children to become capable citizens who are equipped with key competencies to care for the environment. The current Taiwanese environmental education policy has both advantages and disadvantages. In terms of disadvantages, teachers do not know how to teach environmental education classes to cultivate literacy in environmental ethics in children. Environmental education is not easy to implement, and there are many teaching problems (Liang, 2015; Shih, 2013). This study reviews related work to explore the teaching methods that cultivate environmental literacy for children in Taiwan and give teachers a standard for environmental education in the classroom.

This paper uses a documentary analysis. It shows the importance and purpose of environmental education and teaching methods for environmental education in Taiwan. 
It is hoped that such an exploration can cultivate literacy in environmental ethics for children so that they can learn to care for the environment in which they live and influence their peer group to care for their surroundings so that Taiwan's ecology is developed sustainably.

\section{Importance}

Since the implementation of the Environmental Education Act in the United States in 1970, countries and international educational organizations have begun to promote environmental education. Environment education can change human values and establish behavior that addresses environmental problems. The 1972 United Nations Conference on the Human Environment (Conference on the Human Environment) announced that environmental education is a subject on which all countries must work together (Yang, 1993). Since the Stockholm Conference in 1972, the UN system, especially UNESCO and UNEP, has played an important part in the institutional development of $\mathrm{EE}$ and the public recognition of its role in addressing environmental problems (Pablo Ángel Meira Cartea, 2005).

In the 1977 International Environmental Education Conference in Tbilisi, UNESCO defined environmental education as, "an educational process in which individuals and societies recognize their environment and the interactions between the biological, physical and sociocultural components that make up the environment to increase knowledge, skills and values to solve current and future environmental issues individually or collectively" (Yang, 1993). Sustainable development is key to environmental education (Jickling, 2005). During the last 20 years, education for sustainable development (ESD) and its inclusion in the dominant neo-liberal trend of the economy has been the subject of many debates. Environmental educators have championed this new concept and a large group perceive ESD as a higher evolutionary level of the environmental education field, which brings more coherence to environmental conservation initiatives, in terms of environmental policy and social, economic and political policies (Edgar González-Gaudiano, 2005).

The 1992 Earth Summit in Brazil proposed that "Agea 21" (Ageda 21) and sustainable development has become a focus for the United Nations, international organizations and governments. Academic research institutions and non-governmental organizations are currently seeking consensus on ideas through static research or dynamic research, to extend the idea of sustainable development from local environmental and ecological perspectives to the social economy and the implementation system. Environmental ethics has become an essential general course for citizens of the world and is a common responsibility for the citizens of the earth (Yang \& Kao,
2019).

In 2005, the United Nations launched the "Decade of Sustainable Development Education”. Ten years later, "Shaping the Future We Want" was the final report. In the same year, the "Action Plan for Global Sustainable Development Education" emphasized "a beautiful tomorrow, starting today." The sustainable development program of the United Nations demonstrates the importance of "education" and "action" for sustainable development or environmental education (Yang \& Kao, 2019).

In terms of ecology, human beings are currently depleting the natural resources of the earth and contributing to many environmental issues. This human-earth interaction model is based on anthropocentrism (Wang, 2003). Lynn White noted that anthropocentrism originates from traditional Christianity and is the source of the contemporary ecological crisis. This comment has promoted discussions on anthropocentrism (Zhu, 2000). Anthropocentrism is a "people-centered" view. Its essence is that "everything is human-centered."

The behavior of human beings has led to ecological issues such as soil erosion. Arbitrarily extracting natural resources without maintaining the natural ecology exacts a heavy price, in terms of environmental disasters and human suffering. Metaphorically, the relationship between man and the earth is similar to the relationship between astronauts and a spacecraft. In the global environment (spacecraft), resources are limited and must be maintained through proper recycling by humans (spacemen) (Wang, 2003). Therefore, environmental education is important for everyone. Only then can there be a harmonious relationship between man and the natural environment.

Environmental education is a critical part of the elementary education system. The "Curriculum Guidelines for Year 12 Basic Education” was instigated by the Taiwanese Ministry of Education in 2014. In order to enable students to become more closely connected to the environment, issue education must be introduced into the curriculum to cultivate critical thinking and improve problem-solving skills and increase students' sense of responsibility and willingness to take action. There are nineteen issues of social concern, so curriculum design must take account of these issues. The nineteen issues are divided into two categories. Gender education, human rights education, environmental education and marine education are defined as "major issues". Environmental education is one of the 19 issues and teaching must integrate environmental issues into curriculum design (The Ministry of Education, 2014).

\section{Purpose}

"The Curriculum Guidelines of the 12-Year Basic 
Education” were developed based on the spirit of holistic education: taking the initiative, engaging in interaction and seeking a common good to encourage students to become spontaneous and motivated learners. The curriculum also encourages schools to guide students to become motivated and passionate learners, to develop the ability to interact with themselves, others, society, and nature. Schools must also allow students to apply their knowledge to experience the meaning of life and develop a willingness to become engaged in the sustainable development of society, nature and culture, to ensure reciprocity for the common good and to increase children's environmental literacy and maintain a harmonious relationship between man and the natural environment so that the natural environment and human life are seamlessly joined (The Ministry of Education, 2014).

In Taiwan, 'Tien-ren-he-yi' (天人合一)('the harmony between humanity and nature') is a core idea of Chinese traditional culture and is the subject of many studies. Chinese thought comprises environmentally friendly doctrines and values (Hung, 2019) and seeks to maintain a harmonious interaction with the environment in which we live, to extend the life of the environment. People and nature thrive together. Achieving this ideal relies on environmental education.

Taiwan's environmental education regime give students environmentally ethical beliefs and cultivates environmentally literate citizens. Environmental ethics is a core concept for children in environmental education lessons. Environmental education cultivates children who have ethical environmental beliefs and ensures that future citizens are environmentally literate.

In terms of the "Curriculum Guidelines of 12 Year Basic Education," the objectives of environmental education include "awareness of environmental issues", "understanding of environmental knowledge", "clarification of environmental values", "learning of environmental skills" and "practicing behavior that protects the environment. Knowledge, understanding, values, skills and actions form the framework for environmental education. Environmental education is an educational process that clarifies environmental values. The educational regime includes the study of environmental literacy in terms of knowledge, attitudes and skills and the final goal is to address environmental problems (National Academy for Educational Research, 2018; The Ministry of Education, 2014; Yen, Ferng, \& Liu, 2006). The "environment" refers to the location of people and the connection between history and the future. According to the International Union for the Conservation of Nature and Natural Resources (IUCN), "Environmental education is a process of conceptual cognition and value clarification, so as to develop understanding and appreciation of the relationship between human beings, culture and their biological and physical environments”.
The third article of Taiwan's "Environmental Education Law" defines environmental education as the use of educational methods to foster an ethical relationship between people and the environment, to enhance knowledge, skills, attitudes and values that protect the environment and which ensures that people care for the environment and take action in a civic education process for sustainable development (Liang, 2015; The Ministry of Education, 2014).

The cultivation of environmental ethics is the foundation of environmental education and the ultimate purpose of environmental education is to cultivate people with environmentally ethical beliefs and sound environmental attitudes and values and to demonstrate ideal environmental behaviors. This begins with experiencing the surrounding natural environment and caring for life and extends to ecological conservation and environmental protection. Children should participate in outdoor learning and natural experiences and be aware of the beauty, balance and integrity of the natural environment and of biological life so that they learn to care for the lives of animals and plants and understand how man and nature coexist to protect important habitats (The Ministry of Education, 2014).

\section{Teaching Methods}

Environmental ethics includes caring for people (social justice and generational justice), caring for life (animal welfare) and caring for the environment (environmental experience and ecological conservation. The learning phase in elementary school is based on an awareness of ecological balance, caring for life and the relationship between people and the environment. In response to these environmental issues, the study of environmental ethics concerns human beings' ethical relationship with the natural environment (The Internet Encyclopedia of Philosophy, 2019; The Ministry of Education, 2014). It focuses on interaction with the environment to ensure that these interactions are ethical. Children must perceive the beauty and value of biological life and care for the lives of animals and plants. They must learn that people and the environment are interdependent so they must protect their surroundings. This study reviews related works to identify learning methods for environmental education, in order to cultivate ethical beliefs in children so that children can learn to care for the environment in which they live and influence others to care for their surroundings. This will produce a sustainable eco-environment in Taiwan. Teaching methods are detailed in the following sections.

\subsection{Using Picture Books}

The picture book originates from Japan. It is a book with pictures that are supplemented by words. The picture emphasizes the story content and enriches the story in a 
visual form. Picture books are used as a teaching material. Teachers can use picture books about environmental issues for environmental education. The author believes that this stimulates children's interest, improves learning outcomes and enhances children's love for the environment.

Liu and Wang (2003) used qualitative and quantitative methods to design a method to teach about environmental issues using picture books and determined the efficacy of the teaching using classroom observation, worksheets, questionnaires and journal entries. The important findings are as follows: 1. Based on the suggestions and reviews of environmental education experts, workers, experienced teachers and teachers who have experience in using picture books as a teaching medium, the relationship between human development and the natural environment is the subject of teaching activities. Nine picture books were used and related activities were used to help students to understand the relationship between human development and the natural environment and the effect of human development upon the environment, so that students can appreciate the importance of environmental protection and take action to protect the environment. Research objects showed a positive attitude to picture books and the related teaching activities and methods. $96.4 \%$ of students enjoyed reading picture books, $92.9 \%$ of students enjoyed the teaching activities using picture books as a teaching medium and $96.4 \%$ of students said that they would participate again in a similar activity.

Research objects such as picture books are both interesting and functional. In terms of the content and language, children enjoy vivid, realistic picture books and books that increase their knowledge and help them to learn. In terms of the pictures and illustrations, children like books with many well designed pictures and illustrations and books with pictures that allow students to construct a personal story. Using picture books as a medium to teach environmental issues raises children's environmental awareness and increases their environmental knowledge. It also defines children's environmental attitudes. Using picture books for learning activities allows children to identity environmental issues, devise concrete solutions, and commit to protecting the environment (Liu \& Wang, 2003).

\subsection{Watching Eco-Related Films}

Environmental ethics seeks to develop children's attitudes to environmental issues and reflects on the interaction between people and the environment. Media teaching is a common teaching method for children. Children enjoy the films such as "Beyond Beauty TAIWAN FROM ABOVE”, “Our Island - Danish Green Life”, Tzu Chi's "Love the Earth" and "Treasure Food and Water". They discuss the content of the films to understand that there is a very close relationship between
Nature and humans (Lin \& Chen, 2012; Xu, 2004).

Polar bear numbers have been decreasing and male bears sometimes survive by killing young bears. Movies that highlight this issue teach children that because of human damage to the environment, polar ice is melting and polar bears have increasing difficulty in finding food. Children can know nature by movies and to develop attitudes and behaviors that care for the environment and to understand that if nature suffers, humans are adversely affected and some animals die (National Museum of National Science, 2020).

\subsection{Drama Teaching and Learning}

Teaching is an activity that leads to learning. Students also learn that they want to learn and change their behavior. Therefore, teaching incorporates the meaning of tasks and the meaning of success and achievement and learning behavior is also changed. Therefore teaching activities create a dependence between the concept of teaching and the concept of learning (Peters, 1974). Teaching is an activity that leads to the emergence and change of learning behavior in students. Drama can also be used in the environmental ethics curriculum, whereby children learn the importance of caring for the environment by role-playing. This changes the learning behavior of children in terms of accruing environmental knowledge. This increases environmental knowledge and promotes positive attitudes in school children and promotes environmental ethical beliefs that allow children to better care for their environment.

\subsection{Visiting Environmental Sites}

The development of human beings is inseparable from the greater environment of the earth so an environmental curriculum cannot be limited to traditional classroom learning. Teachers must allow children access to real situations and real experiences. Children should visit ecologically damaged areas and recognize the importance of protecting the environment. The author believes that site visits enhance learning outcomes for children. Yunlin County has established a Special Tiger Card at Huwei town, which marks the change in the strata in Yunlin County in the past 20 years. Many local residents are unaware of this initiative so teachers can lead children to observe and experience the phenomenon of sinking (Shih, 2014).

\subsection{Inviting Experts to Give Presentations}

Environmental education experts have a professional understanding of the environment. Teachers should invite experts to the classroom to give presentations and discuss the content of their dialogue with other teachers and students in the context of the environmental curriculum. This increases children's appreciation of the connotations 
of environmental ethics and fosters ethical environmental beliefs that are embodied in behavior. Children learn and understand the importance of protecting their environment.

\subsection{Assigning Homework That Has Environment-Related Topics}

Homework with a theme of environmental education inspires children to observe nature and encourages care for the environment in which they live. Teachers must increase children's awareness of environmental damage and foster a positive attitude toward environmental protection. Teachers should teach children the importance of protecting the ecological environment in a subtle manner. Children should present projects that allow teachers and students to share their experiences in terms of caring for the environment, in order to understand how humans can interact with the environment in a humane manner and to foster better awareness of the environment.

\subsection{Critical Thinking about the Use of Learning Strategies in Environmental Education}

Freire noted that critical thinking cannot be separated from imagination and intuition (Shor \& Freire, 1987). He also noted that teachers should be able to think critically so that they can guide children to think critically (Freire, 1993). In the context of environmental education, environmental ethics and sustainable development require a clarification of values, dialects and attitudes and ethics and morality. The principle of critical thinking uses dialogue thinking and dialectical thinking to encourage children to ask how questions. This learning strategy develops students' ability to think rationally and critically about environmental problems (Kao \& Chang, 2016).

\subsection{Learning Strategies That Involve Problem-Solving}

Children should have a broad base of knowledge and be capable of independent thinking and have problem-solving skills (Shih, 2019). Environmental education develops the essential knowledge, skills and attitudes that allow students to become capable citizens with key environmental competencies. The current environmental education policy in Taiwan is mature and The Ministry of Education focuses on environmental education. Thinking about current environmental problems allows children to learn how to address these environmental problems. A problem-based learning strategy is guided by a teacher's presupposed problem statement and appropriate learning situations are arranged to allow teachers and children to engage in a dialogue that encourages children to explore and brainstorm and to propose solutions that rely on data. This strategy allows children to take responsibility for their own learning (Kao \& Chang, 2016).

\section{Conclusions and Results}

\subsection{Conclusions}

The meaning and value of human life is expressed in terms of the maintenance of life itself (basic survival) and the pursuit of life beyond basic survival. These two strategies are related to the relationship between people and the natural environment (Lin, 2013). Human beings cannot be separated from the natural environment and must interact with it. The process of human interaction with the natural environment has been defined in terms of human beings as the masters of nature so the relationship between human beings and the natural environment is a relationship between the conquerors and the conquered. Therefore, human beings have initiated economic and technological activities that ignore natural environment. In this approach realized significant benefits and material comfort was greatly improved. However, unscrupulous over-exploitation has produced a deepening ecological crisis (Shih, 2013). Therefore, in the process of interaction between human beings and the natural environment, many ecological problems have arisen and continuing to interact with the natural environment in this way will eventually lead to the extinction of mankind. The promotion of environmental education in schools highlights the importance of this thought process.

Environmental education focuses on environmental problems that are caused by human development. Children learn to understand and act on environmental problems that are caused by human development. Pollution problems increased and biodiversity decreased during the rapid industrial development of the 1950s and 1960s. The depletion of resources and the impact of climate change are at the core of environmental education. Environmental education increases awareness, knowledge, attitudes, skills and actions in relation to environmental issues and increases awareness of and sensitivity to environmental issues and knowledge of environmental issues. It promotes positive environmental values, attitudes and skills and encourages environmental action. Environmental education increases awareness of environmental issues and environmental actions. In addition to the accrual of knowledge, it also attaches importance to social participation and action. Environmental education has the ultimate goal of sustainable development by creating a balance between development and the environment and ensuring that there is a just allocation of resources that decreases environmental impact. These are major issues for human development that are addressed by environmental education. Environmental education also seeks to foster an ethical relationship between children and the environment, to enhance the knowledge, skills, attitudes and values of schoolchildren to encourage protection of the environment and cultivates environmental ethics in children. It enables 
children to be more eco-conscious when interacting with their environment and allows them to become responsible citizens who are ecologically aware. "The Environmental Education Act” of Taiwan defines environmental education as the use of educational methods that foster an ethical relationship between people and the environment. It enhances the knowledge, skills, attitudes and values that are necessary for the protection of the environment and encourages children to learn about the environment. The most important element of environmental education is creating an ethical relationship with the environment, so environmental education must convey relevant ethical values to school children so that they can become environmentally responsible citizens. This paper reviews related works to show the importance and purpose of environmental education, and identifies teaching methods that cultivate environmental literacy in children in Taiwan so that children learn to care for the environment in which they live and lead their peer group to care for their surroundings. This creates a sustainable eco-environment in Taiwan and creates sustainable campuses that contribute to a sustainable homeland that can be continuously developed.

\subsection{Results}

Education plays a key role in environmental protection and curriculum development. After the Curriculum Reform in 2001, Taiwan's formal curriculum for environmental education in schools became a major issue in the National Curriculum. This course will be extended to all 12 years of national education (Yang \& Kao, 2019). However, teaching methods are crucial to the success of environmental education. The ultimate purpose of environmental education is to cultivate people with environmentally ethical beliefs who have appropriate environmental attitudes and values and who are inspired to protect the environment of Taiwan. Teaching methods that cultivate environmental literacy in children are:

\subsubsection{Using Picture Books}

Children like picture books and these can be used to educate children about the environment.

\subsubsection{Watching Eco-Related Films}

Teachers should use environmental education videos to encourage children to care for the environment and allow them to appreciate and learn that if people harm the environment, they hurt themselves.

\subsubsection{Drama Teaching and Learning}

Role-playing in drama teaching allows children to understand the importance of caring for the environment.

\subsubsection{Visiting Environmental Sites}

Teachers and students should visit sites where there is environmental or ecological damage or where the environment is pristine, in order to understand the beauty of natural ecology and to learn the importance of caring for the environment.

\subsubsection{Inviting Experts to Give Presentations}

Teachers should invite experts to give presentations to children to share knowledge about environmental issues.

\subsubsection{Assigning Homework with Environment-Related Topics}

Teachers should assign homework with environment-related topics that allow children to learn that there is only one planet and that it must be protected.

\subsubsection{Cultivating critical thinking as a Learning Strategy}

The learning strategy of critical thinking allows students to develop the ability to think rationally and critically about environmental problems.

\subsubsection{Problem-Solving Learning Strategies for Environmental Education}

Thinking about current environmental problems allows children to learn how to address environmental problems.

This paper identifies learning methods that cultivate environmental literacy for children in Taiwan and determines a practicable framework that allows teachers to cultivate ethical environmental beliefs in children, in order to produce adults who care for the environment as part of daily life, protect the environment, save energy, conserve materials and recycle resources to create an environment that is more suitable for human needs. These learning methods allow children to experience environmental issues using a diverse teaching strategy and to understand the importance of protecting the environment. The methods teach children to care for the environment in which they live and to encourage their peer group to care for their surroundings, to create a sustainable eco-environment in Taiwan and to increase the quality of life for Taiwanese citizens.

\section{REFERENCES}

[1] A. Stables. Education for diversity: Making differences. Hampshire, England: Ashgate Publishing, 2003.

[2] B. Jickling. Sustainable development in a globalizing world: A few cautions, Policy Futures in Education, Vol.3, No.3, 251-259, 2005.

[3] C. M. Wang. Ecological foundation and concepts for environmental education, Chinese Journal of Environmental Education, Vol. 2, 9-46, 2003.

[4] E. González-Gaudiano. Education for sustainable development: configuration and meaning, Policy Futures 
in Education Vol.3, No.3, 243-350, 2005.

[5] F. Liang. Current problems and solutions of ecological education in Taiwan, The Journal of Educational Science, Vol.14, No.2, 71-105, 2015.

[6] H. W. Yen, J. Y. Ferng, C. H. Liu. The construction of school environment indictor system in Taiwan. Journal of Taiwan Normal University Education, Vol.51, No.1, 85-102, 2006.

[7] I. Shor, P. Freire. A pedagogy for liberation: Dialogues on transforming education. South Hadley, MA: Bergin \& Garvey, 1987.

[8] J. M. Jue. Confucian perspective on the contrast between anthropocentrism and eco-centrism in western environmental ethics, Legein Society, Vol. 25, 1-40, 2000.

[9] L. C. Yang, T. S. Kao. Review and foresight for the curriculum integration of environmental education, Journal of Educational Research and Development, Vol. 15, No.2, 1-26, 2019.

[10] M. H. Lin. Main philosophical thinking on the issues of environmental education, Legein Semi-Annual Journal, Vol.50, 153-201, 2013.

[11] M. L. Liu, P. L. Wang. A Research on using picture books as the medium to teach environmental issues, Chinese Journal of Environmental Education, Vol.2, 93-112, 2003.

[12] M. Y. Jen, S. J. Hsu. Environmental education empowering community in a rural area: The early development of a community nature center, Journal of environmental education research Vol.2, No.2, 23-58, 2007.

[13] Ministry of Education Republic of China (Taiwan). Curriculum guidelines for year 12 basic education. New Taipei City, Taiwan: The Ministry of Education, 2014.

[14] National Academy for Educational Research. Twelve-year National Education Curriculum Outline: Issue integration instruction manual in elementary, junior and senior high schools. New Taipei City, Taiwan: National Academy for Educational Research, 2018.

[15] National Museum of National Science, 2020. The crisis of polar bear. Retrieved from http:// edresource.nmns.edu.tw/ ShowObject.aspx?id=0b81aa7caa0b81d9f9f80b81aa8ced0 b81a2df71

[16] P. A. M. Cartea. In praise of environmental education. Policy Futures in Education, Vol.3, No.3, 284-295, 2005.

[17] P. Freire. Pedagogy of the city. New York: The Continuum, 1993.

[18] R. Hung. Chinese ecological pedagogy: Humanity, nature, and education in the modern world, Educational Philosophy and Theory, Vol.51, No.11, 1073-1079, 2019.

[19] R. S. Peters. Knowledge and the curriculum. London: Routledge \& Kegan Paul, 1974.

[20] T. S. Kao, T. C. Chang. Making sense of environmental education: Key themes for infusion into the curricula in new education reform, Curriculum \& Instruction Quarterly, Vol.19, No.2, 27-51, 2016.

[21] The Internet Encyclopedia of Philosophy, 2019.
Environmental Ethics. Retrieved from https://www. iep.utm.edu/envi-eth/

[22] Y. H. Shih. A study on teaching methods of "environmental ethics" field in the general curriculum in universities, Journal of Liberal Arts Education, Vol.13, 85-100, 2014.

[23] Y. H. Shih. An examination of the functions of a general education art curriculum in universities, Policy Futures in Education, Vol.17, No.3, 306-317, 2019.

[24] Y. H. Shih. Let elementary school children care for their homeland - The study on the elementary school teachers practice environmental education, New Taipei City Education, Vol.10, 47-50, 2013. 